\title{
The power of renaming
}

\section{Australian Family Physician evolves into Australian Journal of General Practice}

Stephen A Margolis

\section{What's in a name? \\ That which we call a rose \\ By any other word would smell as sweet. ${ }^{1}$}

In 2018, we celebrate the renaming of Australian Family Physician (AFP), Australia's premier MEDLINE-listed, peer-reviewed scientific journal of general practice, to Australian Journal of General Practice (AJGP). What does a name signify? John Stuart Mills noted that 'proper names are not connotative: they denote the individuals who are called by them; but they do not indicate or imply any attributes as belonging to those individuals'. ${ }^{2}$ Put simply, he suggested that a name linked to a specific person or object has no intrinsic meaning.

However, in everyday parlance, the name we attach to a specific person or object is interrelated with meaning. For example, in Japan, renaming schizophrenia with an alternative word 'has effectively reduced stigma levels toward this disorder in adults'. ${ }^{3}$ With increasing recognition of the power of naming, there are ongoing vigorous debates on the renaming of other diseases. For example, should polycystic ovarian disease with metabolic sequelae have a different name to the primarily reproductive version? ${ }^{4}$ Should a more appropriate name be coined for non-communicable disease, the principal cause of death in countries with advanced economies? ${ }^{5}$

General practice manages diseases across the clinical spectrum through patient-centred, holistic care, and has been a key element of the Australian healthcare system for more than 60 years. In 1951, the proposal by Fraser Rose and John Hunt was a critical step in the 1952 formation of the Royal College of General Practitioners (RCGP) in the UK. ${ }^{6}$ The Australian statebased membership organisation of the RCGP collectively created the Australian College of General Practitioners in 1958, which became The Royal Australian College of General Practitioners (RACGP) on receipt of a Royal charter in 1969. ${ }^{7}$

The rapid rise in the development, expansion, consolidation and maturation of general practice as a distinct clinical discipline in Australia has been recorded since 1956 through the members' own science-based journal of record. Initially titled The Annals of General Practice, the name was changed to Australian Family Physician (AFP) in 1971. The term 'family physician' was adopted to distinguish between doctors with specialised knowledge and skills choosing a formal career in primary healthcare and those with only a basic medical degree. ${ }^{8}$ Similarly, the first formal training program for general practitioners (GPs), established in 1973 and funded by the federal government, was titled the Family Medicine Program.

Since then, general practice as a unique discipline has advanced exponentially, culminating in the formal recognition as a distinct specialty in Australia that is on par with other traditional specialties. Specifically, the specialty is titled 'general practice' rather than 'family medicine'. Consequently, as the raison d'etre for the term 'family medicine' no longer exists, AFP now progresses into AJGP. Renaming the journal focuses our attention that general practice is now formally recognised as a discrete and unique discipline. In line with all other medical specialties, the 'coming of age' of general practice parallels the pace, strength and depth of general practice research, with AJGP a key facilitator for publication and dissemination of this important work.
Together with you, our loyal readers and supporters, I look forward to our ongoing journey where $A J G P$ will continue the long-established tradition of AFP in providing informative, contextual information that supports you in ensuring your patients have the best possible outcomes.

\section{Author}

Stephen A Margolis MBBS, MFM, MD, GEM, DRANZCOG, FRACGP, FACRRM, is the Senior Medical Editor of AJGP; Professor, School of Medicine, Griffith University, Queensland; and Medical Officer with the Royal Flying Doctor Service.

\section{References}

1. Shakespeare W. Romeo and Juliet. Washington, DC: Folger Shakespeare Library - Simon \& Schuster, 2004; Act II, Scene II.

2. Mills JS. A system of logic, ratiocinative and inductive. 8th edn. New York: Harper and Brothers, 1900; p. 36

3. Yamaguchi S, Mizuno M, Ojio Y, et al. Associations between renaming schizophrenia and stigmarelated outcomes: A systematic review. Psychiatry Clin Neurosci 2017;71(6):347-62.

4. Dunaif A, Fauser BC. Renaming PCOS - A two-state solution. J Clin Endocrinol Metab 2013;98(11):4325-28.

5. Allen $L N$, Feigl AB. What's in a name? A call to reframe non-communicable diseases. Lancet Glob Health 2017;5(2):e129-30

6. Rose FM, Hunt JH. College of General Practitioners. BMJ 1951;10(2):4736.

7. Margolis SA. Australian Family Physician celebrates sixty years of publication. Aust Fam Physician 2016;45(9):616.

8. Davie G. From general practitioner to family physician. S Afr Med J 1975;49(25):1015-16. 